\title{
Effects of Carburization Time and Temperature on the Mechanical Properties of Carburized Mild Steel, Using Activated Carbon as Carburizer
}

\author{
Fatai Olufemi Aramide ${ }^{a, *}$, Simeon Ademola Ibitoye ${ }^{\mathrm{b}}$, \\ Isiaka Oluwole Oladele ${ }^{\mathrm{a}}$,Joseph Olatunde Borode ${ }^{\mathrm{a}}$ \\ ${ }^{a}$ Metallurgical and Materials Engineering Department, Federal University of Technology, \\ Akure, Ondo State, Nigeria \\ ${ }^{\mathrm{b}}$ Materials Science and Engineering Department, Obafemi Awolowo University, \\ Ile-Ife, Osun State, Nigeria
}

Received: July 31, 2009; Revised: September 25, 2009

\begin{abstract}
Due to the complexity of controlling parameters in carburization, there has been relatively little work on process variables during the surface hardening process. This work focuses on the effects of the carburizing temperature and time on the mechanical properties of mild steel carburized with activated carbon, at 850,900 and $950{ }^{\circ} \mathrm{C}$, soaked at the carburizing temperature for 15 and 30 minutes, quenched in oil, tempered at $550{ }^{\circ} \mathrm{C}$ and held for 60 minutes. Prior carburization process, standard test samples were prepared from the as received specimen for tensile and impact tests. After carburization process, the test samples were subjected to the standard test and from the data obtained, ultimate tensile strength, engineering strain, impact strength, Youngs' moduli were calculated. The case and core hardness of the carburized tempered samples were measured. It was observed that the mechanical properties of mild steels were found to be strongly influenced by the process of carburization, carburizing temperature and soaking time at carburizing temperature. It was concluded that the optimum combination of mechanical properties is achieved at the carburizing temperature of $900{ }^{\circ} \mathrm{C}$ followed by oil quenching and tempering at $550{ }^{\circ} \mathrm{C}$.
\end{abstract}

Keywords: packed carburization, carburizing temperature, activated carbon, hardness

\section{Introduction}

Carburizing is one of the most commonly performed steel heat treatments. For perhaps three thousand years it was performed by packing the low carbon wrought iron parts in charcoal, then raising the temperature of the pack to red heat for several hours. The entire pack, charcoal and all, was then dumped into water to quench it. The surface became very hard, while the interior or "core" of the part retained the toughness of low carbon steel ${ }^{1}$. The engineering of surfaces of components to improve the life and performance of parts used in automobiles and aerospace engineering is an active area of research. Suitable thermal / mechanical / thermomechanical surface engineering treatments will produce extensive rearrangements of atoms in metals and alloys and a corresponding marked variation in physical, chemical and mechanical properties. Among the more important of these treatments are heat treatment processes such immersion hardening, induction hardening and case carburizing ${ }^{2}$.

Automobile components such as rack and pinion, gears, cam shaft valve rocker shafts and axles, which require high fatigue resistance, are normally case hardened by carburizing. The carburizing furnaces are either gas fired or electrically heated. The carburizing temperature varies from 870 to $940{ }^{\circ} \mathrm{C}$ the gas atmosphere for carburizing is produced from liquid or gaseous hydrocarbons such as propane, butane or methane ${ }^{3}$. The study of process parameters in metals during heat treatment has been of considerable interest for some years ${ }^{4,5,6,7}$ but there has been relatively little work on process variables during the surface hardening process ${ }^{8}$ since controlling parameters in carburi- zation is a complex problem. The major influencing parameters in carburization are the holding time, carburizing temperature, carbon potential and the quench time in oil ${ }^{9}$. The present work is focused on the effects of carburizing temperature and holding time on the mechanical properties of carburized mild steel.

\section{Materials and Method}

The materials used for this research work are Mild steel (i.e. AISI/SAE 1020, with the chemical composition shown in Table 1 was sourced from Universal steel company, Ogba Industrial Estate, Ikeja, Lagos.), activated carbon, Industrial engine oil (produced by Petro-Canada; Table 2) as quenching medium.

\subsection{Test specimen preparation}

The mild steel was machined to standard test sample sizes of tensile and impact tests. This was done according to ASTM's specifications on standard tensile and impact sample dimensions.

\subsection{Carburization of mild steel samples}

the prepared test samples were embedded in the activated carbon inside a steel pot which was then tightly sealed with clay cover to prevent the CO from escaping and prevent unwanted furnace gas from entering the steel pot during heating. The furnace temperature was adjusted to the required temperature $\left(850,900\right.$ and $950{ }^{\circ} \mathrm{C}$ for 
Table 1. Chemical composition of the mild steel sample

\begin{tabular}{cccccccccccc}
\hline Element & $\mathrm{C}$ & $\mathrm{Si}$ & $\mathrm{S}$ & $\mathrm{P}$ & $\mathrm{Mn}$ & $\mathrm{Ni}$ & $\mathrm{Cr}$ & $\mathrm{Mo}$ & $\mathrm{V}$ & $\mathrm{Cu}$ \\
Avg content & 0.1999 & 0.1548 & 0.0594 & 0.0459 & 0.5826 & 0.131 & 0.1105 & 0.016 & 0.0013 & 0.384 \\
Element & $\mathrm{W}$ & $\mathrm{As}$ & $\mathrm{Sn}$ & $\mathrm{Co}$ & $\mathrm{Al}$ & $\mathrm{Pb}$ & $\mathrm{Ca}$ & $\mathrm{Zn}$ & $\mathrm{Fe}$ & - \\
Avg content & 0.0076 & 0.0051 & 0.0377 & 0.0098 & 0.0028 & 0 & 0.0001 & 0.0048 & 98.2476 & - \\
\hline
\end{tabular}

Table 2. Typical characteristics of the quenching oil (As specified by the producer: Petro-Canada)

\begin{tabular}{lc}
\hline \multicolumn{1}{c}{ Characteristics } & Values \\
\hline Viscosity of cSt @ $40{ }^{\circ} \mathrm{C}$ & 14.0 \\
Viscosity of cSt @ $100{ }^{\circ} \mathrm{C}$ & 3.2 \\
Viscosity of SUS @ $100{ }^{\circ} \mathrm{F}$ & 74 \\
Viscosity of SUS @ $210{ }^{\circ} \mathrm{F}$ & 37 \\
Flash Point, ${ }^{\circ} \mathrm{C} /{ }^{\circ} \mathrm{F}$ & $173 / 343$ \\
Ramsbottom Carbon Residue, Mass $\%$ & 0.2 \\
Quench Time, seconds & \\
Nickel Ball & 16 \\
Chromized Nickel Ball & 19 \\
\hline
\end{tabular}

each stage respectively) and the loaded steel pot was charged into the furnace. When the furnace temperature reaches the required carburizing temperature, it was then held/soaked at the temperature for the required time (15 and 30 minutes). After the material was held at the specified time, the steel pot was removed from the furnace and the material was quenched in industrial engine oil (which was initially at the ambient atmospheric temperature).

\subsection{Tempering of the carburized samples}

The carburized test samples were then tempered at a temperature of $550{ }^{\circ} \mathrm{C}$, held for one hour, and then cooled in air. After the cycles of heat-treatment, the test samples were subjected to tensile test, impact test and hardness test.

\subsection{Mechanical test}

In each case, test was conducted on three test samples and the mean value was calculated.

\subsection{Tensile testing}

The tensile tests were performed on various samples using Monsanto tensometer. The fracture load for each sample was noted as well as the diameter at the point of fracture and the final gauge length. The initial diameter and initial gauge length for each sample was noted before applying load. The sample was subjected to uniaxial load, at a fixed crosshead speed of $10 \mathrm{~mm} / \mathrm{min}$. From the generated data the ultimate tensile strength and percentage elongation of each sample was calculated.

\subsection{Impact test}

The impact tests were performed on various sample determine the impact strengths by the "V-notch method using the Honsfield Balance Impact Testing Machine. Prior to mounting on the machine, the test sample is notched to a depth of $2 \mathrm{~mm}$ with v-shaped hand file. The notched test sample was then mounted on the impact-testing machine, which is the operated to apply a (constant) impact force on the test sample. The impact strength (the amount of impact energy the specimen absorbed before yielding) was then read off the calibrated scale on the impact testing machine.

\subsection{Hardness test}

In present experimental work, Rockwell hardness was measured on carburized, tempered mild steel samples which are carburized under different temperature range of 850,900 and $950{ }^{\circ} \mathrm{C}$. For each of the sample, test was conducted for 3 times and the average of all the samples was taken as the observed values in each case.

\section{Results and Discussions}

Figures 1, 2, 3, 4, 5 and 6, depict the effects of carburizing temperature on the impact energy, ultimate tensile strength, engineering strain, Young's modulus of elasticity, case hardness and core hardness of the test samples respectively. Table 3 shows the mechanical properties of the carburized, tempered samples.

\subsection{Effect of the experiment on the mechanical properties}

\subsubsection{Absorbed (impact) energy and ultimate tensile strength (uts)}

From Figure 1, it is observed that the absorbed (impact) energy reduces with increase in the carburizing temperature, the impact energy of the samples soaked for 30 minutes ( 0.25 hours) were higher than those of the samples soaked for 15 minutes ( 0.50 hours).

In Figure 2, it is observed that for both series of samples, the ultimate tensile strength (UTS) increases initially with increase in the carburizing temperature and then begins to decrease at around $900{ }^{\circ} \mathrm{C}$ with further increase in the carburizing temperature. It is also observed that initially the UTS of the samples soaked for 15 minutes was higher than those soaked for 30 minutes at the carburizing temperature of $850{ }^{\circ} \mathrm{C}$, but at around $880{ }^{\circ} \mathrm{C}$ there was a 'crossover' when the UTS of the samples soaked for 30 minutes were higher than those of samples soaked for 15 minutes. Comparing these with the properties of untreated as received sample, whose impact energy and UTS are respectively $61.25 \mathrm{~J}_{\text {and }} 800.07 \mathrm{Nmm}^{-2}$, the value of impact energy for as received sample is greater than those of carburized and tempered samples, it is expected that due to increased volume fraction of carbides which were formed in the material, impact strength will be reduced ${ }^{10}$.

Similarly, the UTS of the samples soaked for 15 and 30 minutes were higher than that of as received sample when carburized at $850{ }^{\circ} \mathrm{C}$, the UTS of both initially increased as the carburizing temperature was increased from 850 to $900{ }^{\circ} \mathrm{C}$, though at different rate (see Table 3 and Figure 2), it decreased slightly (856.69 $\mathrm{Nmm}^{-2}$ for the sample soaked for 30 minutes and $799.18 \mathrm{Nmm}^{-2}$ for the sample soaked for 15 minutes) when the carburizing temperature was increased to $950{ }^{\circ} \mathrm{C}^{10,11}$. This agrees with the findings of Guttmann and Burgel ${ }^{12}$, carburization has some influence on the mechanical properties of steels. Also this relationship of the UTS with the carburizing temperature is similar to its relationship 


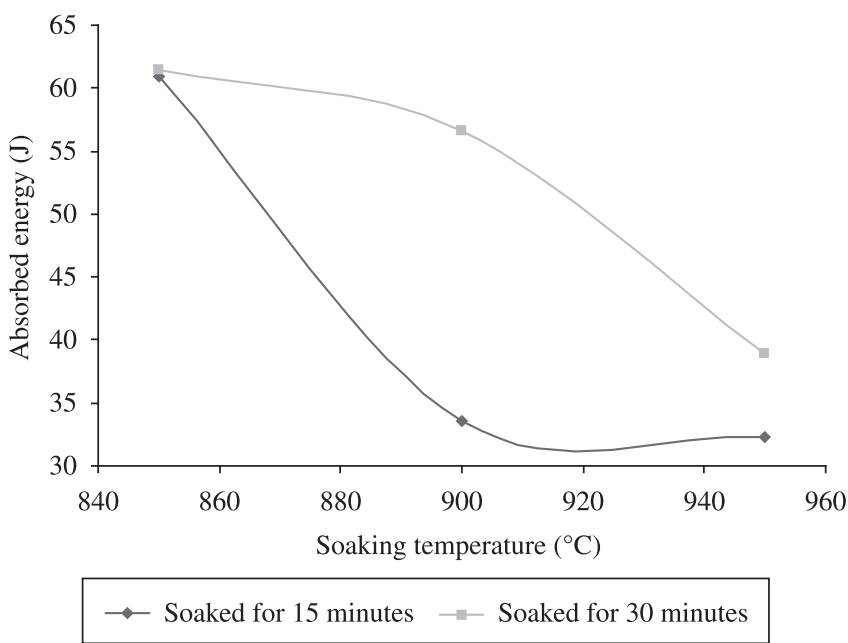

Figure 1. The effect of carburizing temperature on the impact energy of the samples.

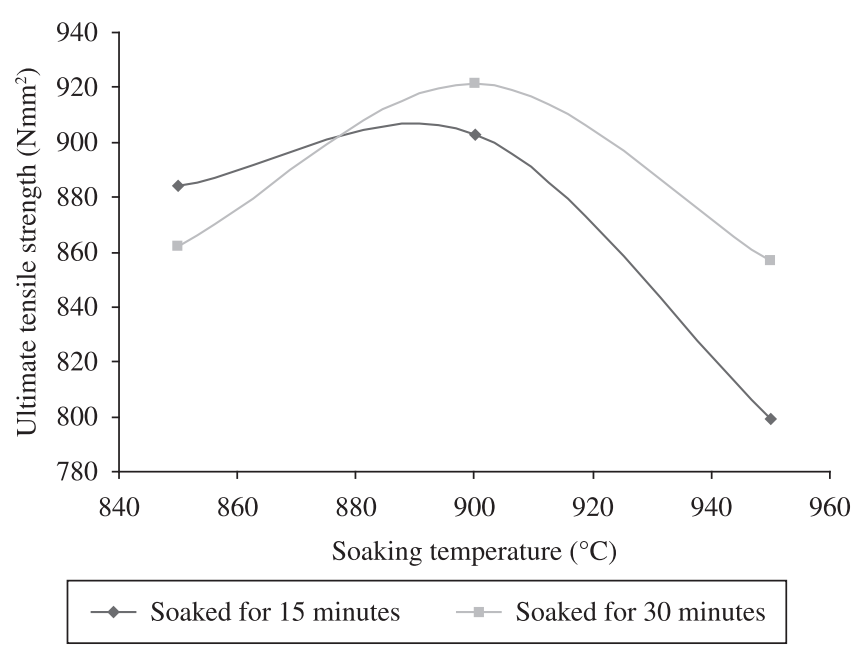

Figure 2. The effect of carburizing temperature on the ultimate tensile strength of the samples.
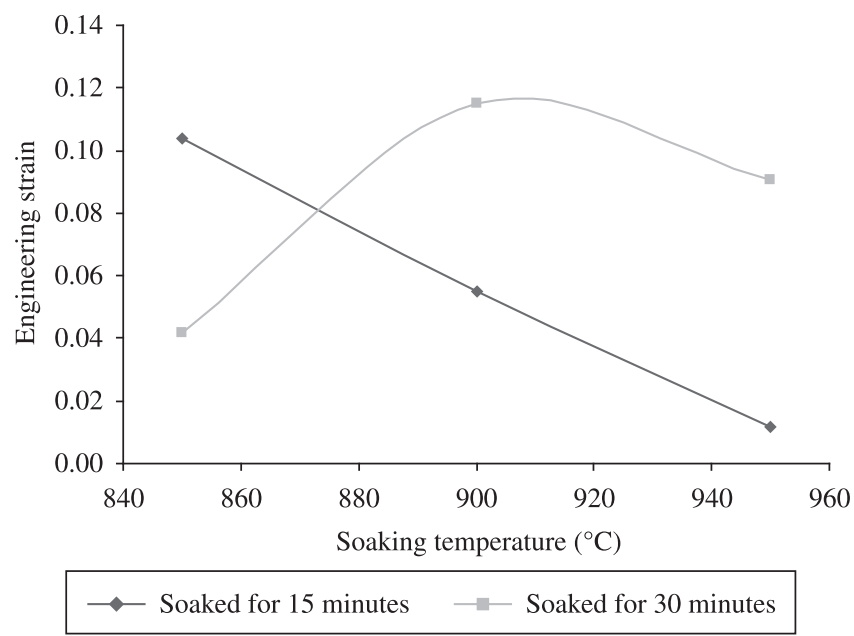

Figure 3. The effect of carburizing temperature on the engineering strain of the samples.

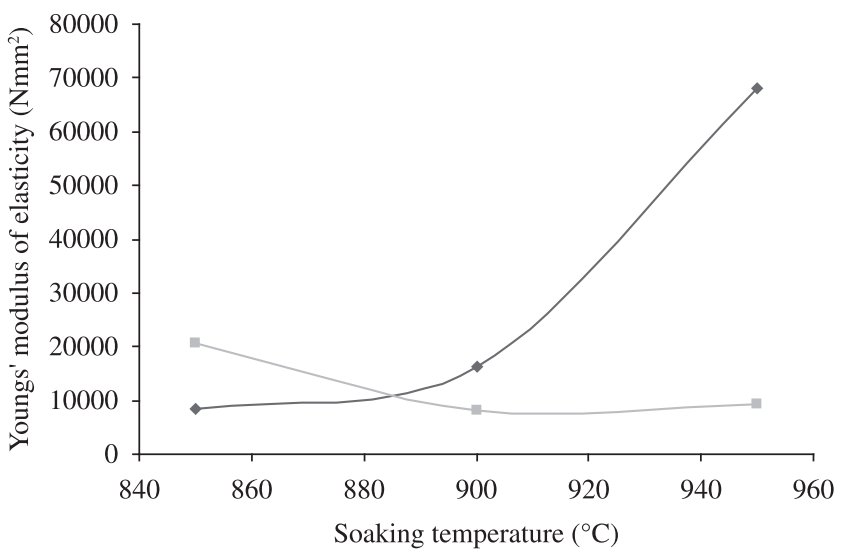

$\rightarrow$ Soaked for 15 minutes $\quad-$ Soaked for 30 minutes

Figure 4. The effect of carburizing temperature on the Young's modulus of elasticity of the samples.
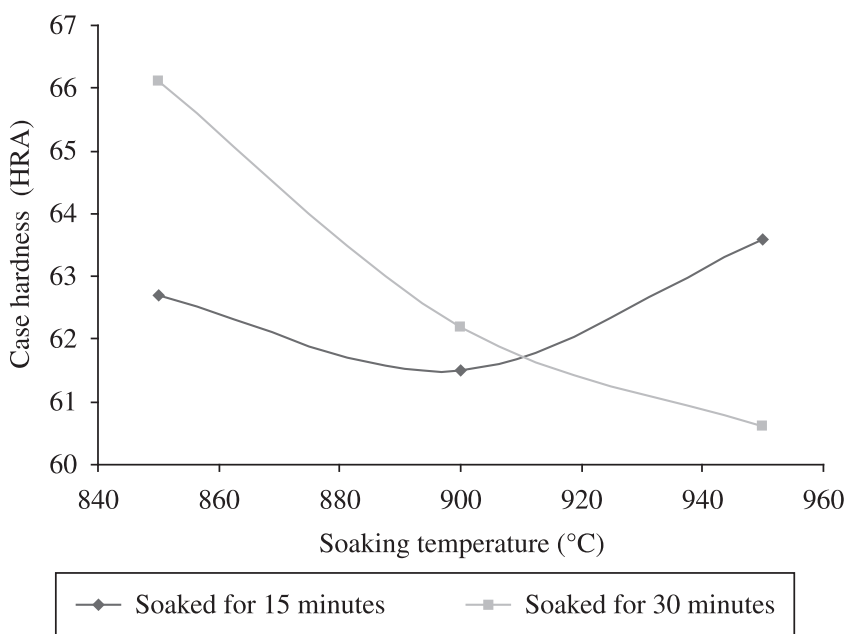

Figure 5. The effect of carburizing temperature on the case hardness of the samples.

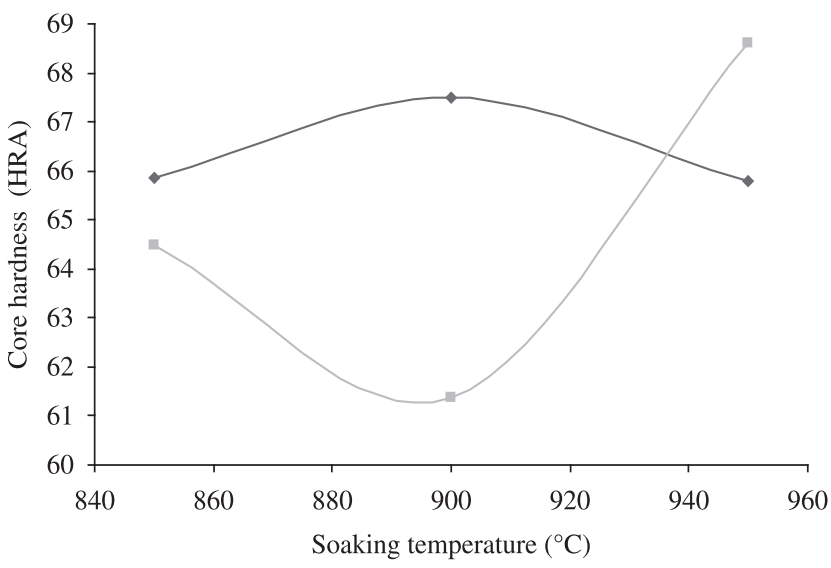

Soaked for 15 minutes Soaked for 30 minutes

Figure 6. The effect of carburizing temperature on the core hardness of the samples. 
Table3. Mechanical Properties of the Carburized, Tempered Samples

\begin{tabular}{cccccccr}
\hline $\begin{array}{c}\text { Time } \\
(\text { minutes })\end{array}$ & $\begin{array}{c}\text { Temperature } \\
\left({ }^{\circ} \mathrm{C}\right)\end{array}$ & $\begin{array}{c}\text { Impact } \\
\text { strength }(\mathrm{J})\end{array}$ & $\begin{array}{c}\text { Core harness } \\
\left(\mathrm{H}_{\mathrm{RA}}\right)\end{array}$ & $\begin{array}{c}\text { Case hardness } \\
\left(\mathrm{H}_{\mathrm{RA}}\right)\end{array}$ & $\begin{array}{c}\mathrm{UTS}\left(\mathrm{N} / \mathrm{mm}^{2}\right) \\
\text { Engineering } \\
\text { strain }\end{array}$ & $\begin{array}{c}\text { Modulus of elasticity } \\
\left(\mathrm{N} / \mathrm{mm}^{2}\right)\end{array}$ \\
\hline 15 & 850 & 60.98 & 65.85 & 62.7 & 883.93 & 0.10385 & 8511.603 \\
15 & 900 & 33.53 & 67.5 & 61.5 & 902.65 & 0.05821 & 15506.786 \\
15 & 950 & 32.31 & 65.8 & 63.6 & 799.18 & 0.01190 & 67157.983 \\
30 & 850 & 61.38 & 64.5 & 66.1 & 861.97 & 0.04335 & 19883.988 \\
30 & 900 & 56.65 & 61.37 & 62.2 & 921.61 & 0.13001 & 7088.762 \\
30 & 950 & 38.94 & 68.6 & 60.6 & 856.69 & 0.09985 & 8579.498 \\
\hline
\end{tabular}

with the percentage carbon content of steel in both annealed and tempered conditions ${ }^{13,14}$, it can be reliably stated that the amount of carbon that diffused into the samples increases with the carburizing temperature.

\subsubsection{Strain}

Furthermore, from Figure 3 it is clearly seen that for the samples soaked at the different carburizing temperature for 15 minutes, the strain reduces linearly with increase in the temperature of carburization: This loss in ductility can be attributed to the volume fraction of carbides formed in the materials ${ }^{14,15}$. While the strain initially increase from its minimum level of 0.04335 (i.e. $4.335 \%$ elongation) at $850{ }^{\circ} \mathrm{C}$, to its maximum of 0.13001 (i.e. $13.001 \%$ elongation) as the carburizing temperature is increased to $900{ }^{\circ} \mathrm{C}$ which then reduced slightly to 0.09985 (i.e. $9.985 \%$ elongation) with further increase in the carburizing temperature to $950{ }^{\circ} \mathrm{C}$ for the samples soaked for 30 minutes $^{10}$. The reason for the initially increase in ductility is due to an increased interface area produced by the carbide formation at grain boundaries which lead to the impurities (cavities and cracks) being redistributed, because their concentration is low the problem of embrittlement is negligible ${ }^{12}$. For those samples soaked for 15 minutes at the carburizing temperature, it can be observed that the strain reduces with increased carburizing temperature, this means that the ductility reduced as it have been stated earlier; it is due to increased volume fraction of carbides which were formed in the material ${ }^{10}$.

\subsubsection{Young's modulus of elasticity}

From Figure 4, it can be observed that the Youngs' modulus of elasticity of the samples soaked for 15 minutes at the carburizing temperature of $850{ }^{\circ} \mathrm{C}$ increases from $8,511.6$ to $15,506.99 \mathrm{Nmm}^{-2}$ (almost double) as the carburizing temperature is increased to $900{ }^{\circ} \mathrm{C}$ and then increased abruptly to $67,157.98 \mathrm{Nmm}^{-2}$ (more than four times) as the carburizing temperature is increased to $950{ }^{\circ} \mathrm{C}$. This shows that the stiffness of this sample increases with increase in the carburizing temperature ${ }^{14,16,17}$. On the other hand for the samples soaked for 30 minutes, the Youngs' modulus at carburizing temperature of $850{ }^{\circ} \mathrm{C}$ reduces from its maximum value of $19,883.99$ to $7,088.76 \mathrm{Nmm}^{-2}$ as the carburizing temperature is increased to $900{ }^{\circ} \mathrm{C}$ and then increased slightly to $8579.5 \mathrm{Nmm}^{-2}$ as the carburizing temperature is increased to $950{ }^{\circ} \mathrm{C}$. This shows that the samples lost their stiffness with increase in the carburizing temperature. The different in the behaviour of these series of sample can be attributed to time of transformation: The 15 minute was not sufficient for complete transformation to take place.

\subsubsection{Case and core hardness}

From Figures 5 and 6 , it is observed that the for the samples soaked for 15 minutes case hardness was 62.7 HRA (while the core hardness was $65.85 \mathrm{HRA}$ ), at the carburizing temperature of $850^{\circ} \mathrm{C}$; when the sample was carburized at $900{ }^{\circ} \mathrm{C}$, the case hardness reduced to 61.5 HRA (while core hardness increased to 67.5 HRA); when the sample was carburized at $950^{\circ} \mathrm{C}$, the case hardness then increased to 63.6 HRA (while the core hardness reduced to 65.8 HRA). Comparing these with the hardness of as received samples of 51.2 HRA it is glaring that there was actually carbon enrichment in the carburized samples. Furthermore, for those samples soaked for 30 minutes at different carburizing temperatures the case hardness was 66.1 HRA (while the core hardness was 64.5 HRA), at the carburizing temperature of $850{ }^{\circ} \mathrm{C}$; when the sample was carburized at $900{ }^{\circ} \mathrm{C}$, the case hardness reduced to 62.2 HRA (while core hardness reduced to $61.37 \mathrm{HRA}$ ); when the sample was carburized at $950{ }^{\circ} \mathrm{C}$, the case hardness then reduced to 60.6 HRA (while the core hardness increased to 68.6 HRA).

It can be observed from Figures 1, 2, and 3 that the samples soaked for 30 minutes have better property being considered within the soaking temperature range of 900 and $950^{\circ} \mathrm{C}$. From Figure 4, it is glaring that the high Youngs' modulus of the samples soaked for 15 minutes is responsible for the low impact strength of the said samples in Figure 1. From Figures 5 and 6, only the sample carburized at $900{ }^{\circ} \mathrm{C}$ soaked for 30 minutes showed a trend of hard case with softer core, hence it is considered the optimum carburization process route.

\section{Conclusion}

From the discussions so far it is concluded that:

- The mechanical properties of mild steels were found to be strongly influenced by the process of carburization, carburizing temperature soaking time at carburizing temperature;

- The carburization treatment followed by the oil quenching and tempering at $550^{\circ} \mathrm{C}$ strongly influence the hardness and tensile strength of mild steels;

- The carburization process decreases the impact energy (toughness) of the mild steels. And the toughness is decreases with increase in the carburization temperature; and

- The optimum combination of mechanical properties is achieved at the carburizing temperature of $900^{\circ} \mathrm{C}$ soaked for 30 minutes followed by oil quenching and tempering at $550{ }^{\circ} \mathrm{C}$ for 60 minutes.

\section{References}

1. Prime M.B., Prantil V.C., Rangaswamy P and García F.P. In: Böttger A.J., Delhez R. and Mittemeijer E.J., Editors. Residual Stress Measurement and Prediction in a Hardened Steel Ring. Materials Science Forum; Residual Stress ECRS 5. Stamford: Thomson Scientific; 2006. p 223-228.

2. Child HC. Surface hardening of steels. London: Oxford University Press; 1980.

3. Rajan TV, Sharma CP and Sharma A. Heat Treatment Principles and Techniques. New Delhi: Prentice Hall; 1994. 
4. Denis S. Coupled temperature stress, phase transformation calculation model numerical illustration of the internal stresses evolution during cooling of a eutectoid carbon steel cylinder. Metallurgical Transaction A 1987; 18A:1203-1287.

5. Leblond JB. Mathematical modeling of transformation plasticity in steels II: Coupling with strain hardening phenomena. International Journal of Plasticity 1989; 5(6):573-591.

6. Wang KF, Chandrasekar S and Yang HTY. Experimental and computational study of the quenching of carbon steel. International Journal of Manufacturing Science and Engineering 1997; 119(3):257-265.

7. Liu CC, Xu XJ and Liu Z. A FEM modeling of quenching and tempering and its application in industrial engineering. Finite Elements in Analysis and Design 2003; 39(11):1053-1070.

8. Xu DH, Kuang ZB. A study on the distribution of residual stress due to surface induction hardening. International Journal of Engineering Materials and Technology 1996; 118(2):571-575.

9. Shewmon GP. Di_usion in solids, series in material science and Engineering. Tokyo: Mc Graw Hill; 1963.

10. Ward DM. Influence of carburization on the properties of furnace tube alloys. In: Guttmann V and Merz M. (Eds.). Corrosion and mechanical stress at high temperatures. London: Applied Science Publishers Ltd.; 1981. p. 71-83.

11. Hochman R and Burson J. The Fundamentals of Metal Dusting. New York: API Division of Refining; 1966. p. 331.

12. Guttmann V and Burgel R. The creep behaviour of HK40 and alloy $800 \mathrm{H}$ in a carburizing environment. In: Guttmann, V. and Merz, M. (Eds.). Corrosion and mechanical stress at high temperatures. London: Applied Science Publishers; 1981. p. 71-83.

13. Singh V. Physical Metallurgy. 1 ed. Delhi: Standard Publishers Distributors; 2005. p. 419.

14. Higgins RA. Engineering Metallurgy. 5 ed. Kent: ELBS; Edward Arnold Publishers Ltd.; 1991. p. 40-162. (part 1, Applied physical metallurgy).

15. Ennis PJ and Lupton DF. The relationship between carburization and ductility loss. Behaviour of High Temperature Alloys in Aggressive Environments. In: Proceedings of the International Conference; 1979, Oct. 15-18. London: The Metals Society; 1980. p. 979-991.

16. Aramide FO, Oladele IO and Folorunso DO. Evaluation of the effects of fiber volume fraction on the mechanical properties of a polymer matrix composite. Leonardo Electronic Journal of Practices and Technologies 2009; (14):134-141.

17. Callister WD. Materials science and Engineering an Introduction. New York: John Wiley and Sons; 2000. 
